\title{
Effect of socio-demographic and health factors on the association between multimorbidity and acute care service use: population-based survey linked to health administrative data
}

Kathryn A. Fisher ${ }^{1 *}$ (D), Lauren E. Griffith ${ }^{2}$, Andrea Gruneir ${ }^{3,4}$, Ross Upshur ${ }^{5}$, Richard Perez ${ }^{6}$, Lindsay Favotto ${ }^{6}$, Francis Nguyen ${ }^{6}$, Maureen Markle-Reid ${ }^{1,2}$ and Jenny Ploeg ${ }^{1}$

\begin{abstract}
Background: This study explores how socio-demographic and health factors shape the relationship between multimorbidity and one-year acute care service use (i.e., hospital, emergency department visits) in older adults in Ontario, Canada.

Methods: We linked multiple cycles (2005-2006, 2007-2008, 2009-2010, 2011-2012) of the Canadian Community Health Survey (CCHS) to health administrative data to create a cohort of adults aged 65 and older. Administrative data were used to estimate one-year service use and to identify 12 chronic conditions used to measure multimorbidity. We examined the relationship between multimorbidity and service use stratified by a range of socio-demographic and health variables available from the CCHS. Logistic and Poisson regressions were used to explore the association between multimorbidity and service use and the role of socio-demographic factors in this relationship.

Results: Of the 28,361 members of the study sample, $60 \%$ were between the ages of 65 and 74 years, $57 \%$ were female, $72 \%$ were non-immigrant, and over 75\% lived in an urban area. Emergency department visits and hospitalizations consistently increased with the level of multimorbidity. This study did not find strong evidence of moderator or interaction effects across a range of socio-demographic factors. Stratified analyses revealed further patterns, with many being similar for both services - e.g., the odds ratios were higher at all levels of multimorbidity for men, older age groups, and those with lower household income. Rurality and immigrant status influenced emergency department use (higher in rural residents and non-immigrants) but not hospitalizations. Multimorbidity and the range of socio-demographic variables remained significant predictors of service use in the regressions.
\end{abstract}

(Continued on next page)

* Correspondence: fisheka@mcmaster.ca

'School of Nursing, McMaster University, HSC 2J36, 1280 Main Street West, Hamilton, Ontario L8S 4K1, Canada

Full list of author information is available at the end of the article

(c) The Author(s). 2021 Open Access This article is licensed under a Creative Commons Attribution 4.0 International License, which permits use, sharing, adaptation, distribution and reproduction in any medium or format, as long as you give appropriate credit to the original author(s) and the source, provide a link to the Creative Commons licence, and indicate if changes were made. The images or other third party material in this article are included in the article's Creative Commons licence, unless indicated otherwise in a credit line to the material. If material is not included in the article's Creative Commons licence and your intended use is not permitted by statutory regulation or exceeds the permitted use, you will need to obtain permission directly from the copyright holder. To view a copy of this licence, visit http://creativecommons.org/licenses/by/4.0/ The Creative Commons Public Domain Dedication waiver (http://creativecommons.org/publicdomain/zero/1.0/) applies to the data made available in this article, unless otherwise stated in a credit line to the data. 
(Continued from previous page)

Conclusions: Strong evidence links multimorbidity with increased acute care service use. This study showed that a range of factors did not modify this relationship. Nevertheless, the factors were independently associated with acute care service use, pointing to modifiable risk factors that can be the focus of resource allocation and intervention design to reduce service use in those with multimorbidity. The study's results suggest that optimizing acute care service use in older adults requires attention to both multimorbidity and social determinants, with programs that are multifactorial and integrated across the health and social service sectors.

Keywords: Acute care service use, Multimorbidity, Socio-demographic factors, Population-based cohort study, Older adults, Emergency department use, Hospital use

\section{Background}

Multimorbidity - the coexistence of two or more chronic conditions in the same person -is highly prevalent in older adults. Studies from a range of settings and populations show an increasing prevalence of multimorbidity, with estimates ranging from 65 to $98 \%$ in those > 65 years of age [1-6]. Studies from around the world also report that the prevalence of multimorbidity is on the rise due to global aging, including increases in Canada, from 17.4 to $24.3 \%$ (27\% increase) [7], the Netherlands, from 12.75 to $16.2 \%$ (12\% increase) [8], and the U.S. from 22 to $30 \%$ (36\% increase) [9]. Multimorbidity has been associated with decreased physical functioning $[10,11]$, lower quality of life [11], higher mortality [12], and increased healthcare service use and cost $[13,14]$. It is now regarded as one of the largest global healthcare challenges of the twenty-first century $[6,7,15]$.

This paper is concerned with the impact of multimorbidity on healthcare utilization, a topic for which detailed knowledge is incomplete [16]. Lehnert et al.'s systematic review [13] found that the majority of the 35 included (observational) studies showed a positive association between multimorbidity and service use/cost in older adults. This review and studies published after it note that while multimorbidity and healthcare service use are strongly related, the evidence has been inconsistent on how other sociodemographic factors known to be independently related to multimorbidity and healthcare service use impact the relationship between the two $[13,17]$.

Studies, most published since the Lehnert et al. review, have identified a range of factors affecting healthcare service use in older adults with multimorbidity, including age and sex [17-21], socio-economic status [17], eligibility for free medical care [18], living alone [22], and impaired activities of daily living [19]. However, the results for these factors have been inconsistent. Van den Bussche et al. [19] found that service use was related to multimorbidity, but no differences in this relationship were seen across sex or age groups. Fortin et al. [23] found sex differences where multimorbidity was higher in women than men yet men had higher healthcare use. Results similar to Fortin et al.'s have been reported by others [17, 19]. Inconsistent age/sex interactions have been seen, with one study showing that increasing age was associated with increasing physician consultations in men and decreasing consultations in women [17], and another showing a larger age effect on consultations in women versus men [18]. Some studies have found lower socio-economic status was associated with lower healthcare service use [17], and others have found no association [24]. This heterogeneity of study findings can reflect different levels of multimorbidity [25], inaccurate or incomplete correlates data [17], and geographical differences in healthcare systems and care delivery models [15, 26].

Many studies to date have treated socio-demographic factors as covariates that are adjusted for in regression analyses examining the relationship between multimorbidity and healthcare service use, or examined only a few socio-demographic factors. Adjusting for confounders in regression models does not explore potential effect modification, i.e., whether the relationship between multimorbidity and healthcare service use is consistent across levels of the socio-demographic factors. In many practice settings, resources to implement interventions are limited, thus it may not be possible to treat an entire population. Information on moderator and interaction effects can help to identify groups of individuals who would or would not benefit, or who would benefit to the greatest extent, from an intervention. Even in settings where resources are not limited, some individuals may benefit and others not from an intervention, in which case resources should target those that benefit and refrain from treating those that do not. Also, it may not be possible to intervene directly on the primary exposure of interest, such as multimorbidity. In such cases, intervention design can turn to the modifiable risk factors that eliminate much or some of the effect of the primary exposure on the outcome (healthcare service use in this study). Finally, studies that examine only a few socio-demographic factors may be missing key confounders. Therefore, it is important to consider a broad range of factors to better understand the role of multimorbidity relative to these other factors in shaping healthcare service use. 
The purpose of this study was to examine the relationship between multimorbidity and acute care service use (i.e., hospital and emergency department visits) in older adults in Ontario, Canada, and how socio-demographic factors impact this relationship. We focused on acute care services because these are among the most expensive health care services, thus of great interest to policy and decision makers. We used a large-scale populationbased survey linked to administrative data to explore the associations among multimorbidity, acute care service use, and a comprehensive range of socio-demographic factors. The findings can inform future explanatory theories that deepen our understanding of multimorbidity and its impacts.

\section{Methods}

\section{Study design and setting}

This is a retrospective cohort study in which we used data from four cycles of the Canadian Community Health Survey (CCHS) linked with health administrative data from Ontario, Canada's largest province. Ontario has a population of approximately 14 million residents with the vast majority receiving provincial health insurance coverage for acute care services. Health administrative databases were used to obtain the one-year health service use from the index date of each of the four CCHS cycles. Since the distribution of health service use and other variables were similar over the time spanning the four CCHS cycles, we pooled the results for the CCHS cycles.

\section{Data sources}

The CCHS is a national cross-sectional survey that collects information related to health status, health care utilization, and health determinants for the Canadian population. CCHS cycles 2005-2006 [27], 2007-2008 [28], 2009-2010 [29], and 2011-2112 [30] were chosen to maximize sample size and ensure consistency in the framing of questions relating to CCHS items used in this study. The four CCHS cycles were administered in participants' homes using computer-assisted personal interviewing and participants in Ontario were asked if they would consent to have their CCHS data linked to provincial administrative data holdings. The index date for linkage was the participant's CCHS interview date. Administrative databases used in the study were the: Registered Persons Database (demographics); Ontario Health Insurance Plan (OHIP) (physician visits); Discharge Abstract Database (inpatient hospitalizations); National Ambulatory Care Reporting System (emergency department other ambulatory contacts); Same Day Surgery (same-day surgeries, procedures); and Ontario Drug Benefit (outpatient prescription claims). Two additional data sources were accessed for specific diagnostic information on chronic conditions: the Ontario Mental Health Reporting System and the Ontario Cancer Registry. More information on theses databases is provided in Additional File 1. All data are held at ICES, where they were linked using encoded identifiers and analyzed. ICES is an independent, non-profit research institute funded by an annual grant from the Ontario Ministry of Health and Long-Term Care. As a prescribed entity under Ontario's privacy legislation, ICES is authorized to collect and use health care data for the purposes of health system analysis, evaluation and decision support. Secure access to these data is governed by policies and procedures that are approved by the Information and Privacy Commissioner of Ontario. The study received approval from the Hamilton Integrated Research Ethics Board at McMaster University (certificate \#13-590) and renewed yearly as required.

\section{Study sample}

We included Ontario CCHS participants who responded to any of the included CCHS cycles and who agreed to have their data linked to the health administrative data. We excluded those who were under 65 or over 85 years of age $(n=103,377)$ because those under 65 to have health service use substantially different from older adults [31] and there was only a small number of CCHS participants over age 85 . We excluded people who could not be identified as Ontario residents $(n=94)$, who did not have health system contact within the 5 years prior to their survey date $(n=161)$, who resided in long-term care $(n=158)$ or received hospice or palliative care services $(n=322)$, who participated in more than one CCHS cycle (we chose only the first cycle to avoid duplicate participants in the pooled data, $n=580$ ), who did not report their chronic disease status $(n=1016)$ and who were ineligible for OHIP coverage at index $(n=71)$. The final sample included 28,361 individuals (see Fig. 1).

\section{Chronic conditions and multimorbidity}

We identified 12 chronic conditions: Alzheimer's diseases/dementia, anxiety/depression, arthritis, cancer, asthma, chronic obstructive pulmonary disease (COPD), diabetes, heart disease, hypertension, inflammatory bowel disease, stomach or intestinal ulcers, and stroke. These conditions were chosen because they could be identified in the administrative data, are prevalent in older adults, and are frequently reported in the literature on multiple chronic conditions [7, 32, 33]. Chronic conditions were identified as either entry into a diseasespecific database created at ICES or using an algorithm that searched for specific diagnostic codes and/or outpatient prescription claims within the 5 years prior to baseline. More details about each diagnostic definition can be found in Additional File 2. 


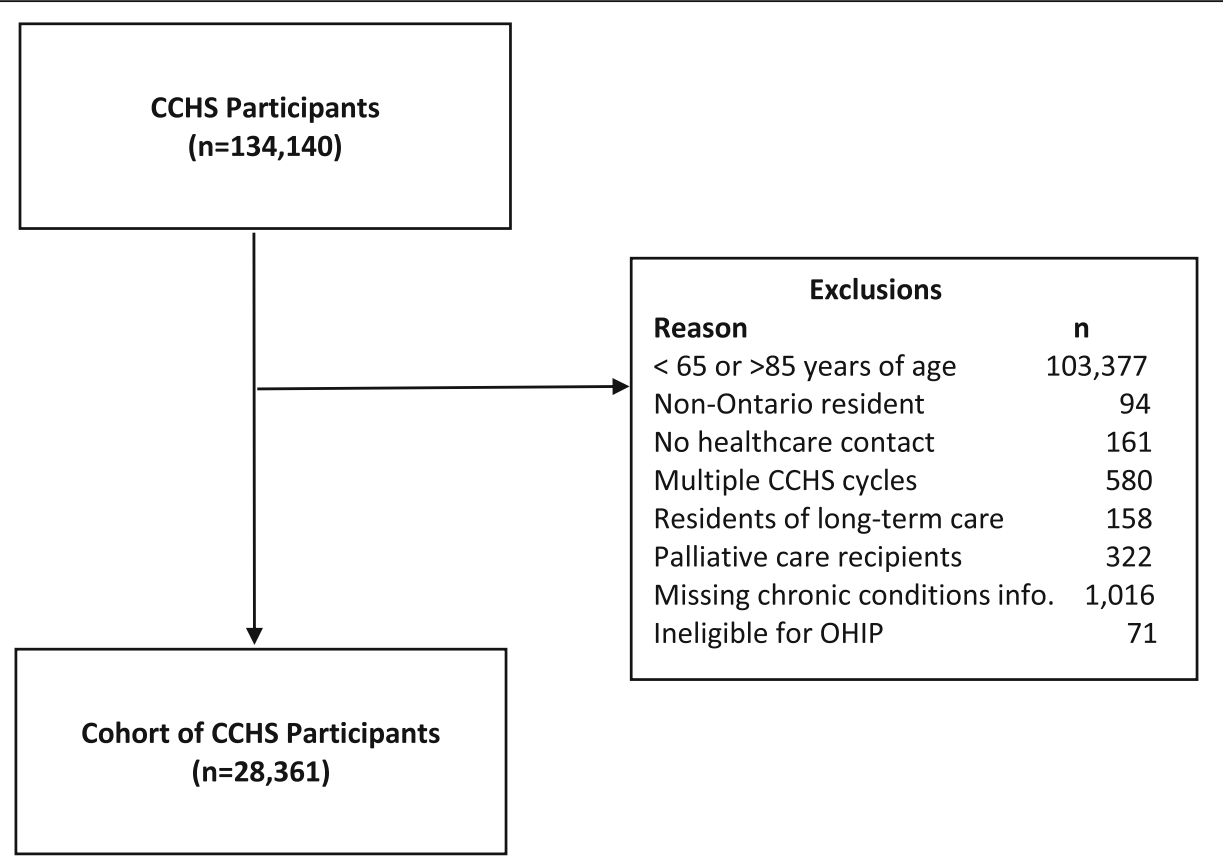

Fig. 1 Study cohort of Canadian Community Health Survey participants (Ontario) who consented to administrative data linkage. Legend: CCHS Canadian Community Health Survey, OHIP - Ontario Health Insurance Plan

Multimorbidity was operationalized as a count of individual chronic conditions $(0,1,2,3,4$, or 5 or more).

\section{Acute care service use}

The outcome in this study was acute care service use, hospital admissions and emergency department visits that occurred in the 12 months after the CCHS interview date. The analyses included two measures for each service: a dichotomous variable (any visit/admission over one year) and a count variable (number of visits/admissions over one year).

\section{Socio-demographic \& Health Status Variables}

The socio-demographic and health status variables selected for the study were determined by those available from the CCHS, guided by Anderson and Newman's Behavioural Model of Health Care Utilization which identifies the following 3 determinants of health service use: need, enabling, and predisposing factors [34, 35]. Need is determined by a person's perceived need for health services, which in turn is a function of selfperceived health, activities of daily living (ADLs) or restricted activity, self-reported symptoms, quality of life, etc. Enabling factors include a person's income, health insurance status, and access to regular care. Predisposing factors include demographic variables, attitudes, and beliefs. Anderson and Newman's model has been primarily used for explaining health care utilization in the general population, with strong evidence of a socio-economic gradient in both developed and developing countries
[36-40]. Our goal in using the Anderson and Newman model was to ensure that we were comprehensive in capturing the main determinants that have been hypothesized to shape health service use. Predisposing variables in our study included sex, age, marital status and living arrangement; enabling factors included education, household income, and rurality; and needs-based variables were captured by the need for any assistance with daily activities, and two health-status variables (self-perceived physical and mental health). Additional File 3 provides further details on how these variables were defined and operationalized in the study.

Multiple imputation using a discriminant function method [41] was employed to address missing data, which only occurred for certain CCHS variables. All CCHS data and chronic conditions and a flag indicating death during a five-year prospective observation period from administrative data were used to impute missing data. Additional file 3 shows the amount of missing data for each variable, with household income have the highest level of missing data (7.56\%), followed by education (3.22\%) and self-reported mental health (2.25\%).

\section{Statistical analysis}

Our main interest was the role of socio-demographic and health status factors in moderating the association between multimorbidity and acute care service use, in other words, the interaction of these variables with multimorbidity to influence service use. We began by conducting bivariate analyses exploring the association 
between multimorbidity and acute care service use stratified by each socio-demographic and health status variable. Logistic regression was employed in the bivariate analysis, modelling any vs. no acute care service over one year. All odds ratios (ORs) used a reference of 0 chronic conditions for one of the subgroups, e.g., the OR for any hospitalization during the past year for females and males with 1 chronic condition represent the odds in those with 1 chronic condition compared to females with no chronic conditions. Analyses showing differences in the multimorbidity-service use relationship across strata, were followed up with more detailed stratified analyses to determine whether the patterns were similar across demographic subgroups. For example, a difference in the relationship between multimorbidity and service use between males and females was followed with further stratified analyses (e.g., age and sex) to determine if the sex difference was similar across age groups. Given the large number of socio-demographic and health status variables in the study, it was not feasible to explore the interactions of multimorbidity with all variables. Therefore, we examined the patterns in the stratified analyses, and identified a subset of variables for which the relationship between multimorbidity and acute care service use showed evidence of significant variability across subgroups. Because of the significant role of age and sex in healthcare analyses, the regression models that explored interaction effects were run separately for each age/sex stratum (i.e., males 65-74 years, males 75-84 years, females 65-74 years, females 75-84 years). We also performed multivariable regressions, which included multimorbidity and all the socio-demographic and health status variables, to adjust for these factors in exploring the association between multimorbidity and acute care service use. Logistic regression was used for the dichotomous dependent variable (any versus no health service use) and Poisson regression was used to analyze the number of health service encounters. Interactions between multimorbidity and the covariates were explored in the regressions. Regressions did not include the CCHS cycle as a variable because early analyses showed no evidence of changes in sociodemographic or service use variables over time.

SAS version 9.4 was used for all statistical analyses, and the level of significance used throughout the study was alpha $=0.05$.

\section{Results}

\section{Socio-demographic, health status and acute care service} use

Of the 28,361 members of the study sample, $60 \%$ were between the ages of 65 and 74 years, $57 \%$ were female, $72 \%$ were non-immigrant, and over $75 \%$ lived in an urban area and had annual household incomes below $\$ 80,000$. While $72 \%$ perceived their mental health to be very good or excellent, fewer (46\%) perceived their physical health to be so and $44 \%$ reported having $3+$ chronic conditions. The majority (80\%) did not need help with basic daily tasks, such as meal preparation, routine household errands, personal care etc. During the previous year, $7 \%$ had at least one emergency department visit and $12 \%$ had at least one acute care episode (see Table 1).

\section{Stratified analyses: relationship between acute care service use and multimorbidity}

Given the large number of stratification variables, the main body of the paper provides the figures where key relationships were seen for any hospital use, with the remaining stratified figures for hospital use provided in Additional File 4 and all figures for any emergency department use provided in Additional File 5. Fig. 2a-f show the odds ratios (ORs) for any hospital use within 1 year of CCHS index date by level of multimorbidity (number of chronic conditions), stratified by selected socio-demographic and health status variables, i.e., sex, age, household income, needs help, self-perceived mental health and self-perceived physical health.

There was little evidence of effect modification across the range of socio-demographic and health status variables. Hospitalizations and emergency department visits consistently increased with the level of multimorbidity and stratified analyses revealed further patterns independent of the level of multimorbidity. The ORs for both services were higher at all levels of multimorbidity for: men (vs women) (Fig. 2a, Fig. 5 a - Additional File 5), older age groups (age 75-84 vs 65-74) (Fig. 2c, Fig. 5 b - Additional File 5), those with lower annual household income (below $\$ 30,000$ vs above) (Fig. 2e, Fig. 5 c - Additional File 5), those that needed help with daily tasks (Fig. 2d, Fig. $5 \mathrm{~d}$ - Additional File 5), those with lower perceived mental and physical health (Fig. 2e \& f, Figs. 5 e \& f - Additional File 5), and those with less education (Fig. $4 \mathrm{~d}$ - Additional File 4, Fig. 5 j - Additional File 5). Different OR patterns for the two services were seen for rurality and immigrant status, which did not appear to impact hospitalizations (Figs. $4 \mathrm{~b}$ and $\mathrm{c}-$ Additional File 4) yet impacted emergency department use (higher in rural vs urban residents and non-immigrants vs immigrants) (Figs. 5 h \& i - Additional File 5). The ORs for both services did not differ substantially by marital status (Fig. 4 a - Additional File 4, Fig. 5 g - Additional File 5) or living arrangement (Fig. 4 e - Additional File 4, Fig. 5 k Additional File 5).

\section{Interaction results}

We examined the interactions between the following three variables and multimorbidity based on an assessment of 
Table 1 Prevalence of selected socio-demographic and health status characteristics, multimorbidity and acute care service use

\begin{tabular}{|c|c|c|c|}
\hline Characteristic & Category & Frequency $(n)$ & Percentage (\%) \\
\hline \multirow[t]{2}{*}{ Age } & $65-74$ & 16,979 & 59.87 \\
\hline & $75-84$ & 11,382 & 40.13 \\
\hline \multirow[t]{2}{*}{ Sex } & Male & 12,093 & 42.64 \\
\hline & Female & 16,268 & 57.36 \\
\hline \multirow[t]{2}{*}{ Immigrant Status } & Immigrant & 7736 & 27.28 \\
\hline & Non-Immigrant & 20,625 & 72.72 \\
\hline \multirow[t]{3}{*}{ Education } & Post Secondary Degree & 12,661 & 44.64 \\
\hline & Secondary School Degree & 6139 & 21.65 \\
\hline & No Diploma & 9561 & 33.71 \\
\hline \multirow[t]{3}{*}{ Household Income } & Under $\$ 30,000$ & 10,382 & 36.61 \\
\hline & $\$ 30,000$ to $\$ 79,999$ & 13,723 & 48.39 \\
\hline & $\$ 80,000$ or more & 4256 & 15.01 \\
\hline \multirow[t]{2}{*}{ Living Arrangement } & Living with others & 16,583 & 58.47 \\
\hline & Living Alone & 11,778 & 41.53 \\
\hline \multirow[t]{2}{*}{ Geography } & Urban & 21,402 & 75.46 \\
\hline & Rural & 6959 & 24.54 \\
\hline \multirow[t]{2}{*}{ Instrumental Activities of Daily Living (IADLs) } & Does not need help with basic tasks & 22,732 & 80.15 \\
\hline & Needs help with basic tasks & 5629 & 19.85 \\
\hline \multirow[t]{3}{*}{ Self perceived physical health } & Excellent/Very Good & 12,937 & 45.62 \\
\hline & Good & 9027 & 31.83 \\
\hline & Fair or Poor & 6397 & 22.56 \\
\hline \multirow[t]{3}{*}{ Self perceived Mental Health } & Excellent/Very Good & 20,369 & 71.82 \\
\hline & Good & 6490 & 22.88 \\
\hline & Fair or Poor & 1502 & 5.3 \\
\hline \multirow[t]{4}{*}{ Chronic Conditions } & 0 & 2457 & 8.7 \\
\hline & 1 & 5786 & 20.4 \\
\hline & 2 & 7694 & 27.1 \\
\hline & $3+$ & 12,424 & 43.80 \\
\hline \multirow[t]{2}{*}{ Emergency Department Visits } & Any visit (past year) & 1895 & 6.7 \\
\hline & Mean (standard deviation) & $1.74(1.76)$ & \\
\hline \multirow{2}{*}{$\begin{array}{l}\text { Acute Care Episode (Hospital or Emergency } \\
\text { Department Visit) }\end{array}$} & Any episode (past year) & 3515 & 12.4 \\
\hline & Mean (standard deviation) & $1.34(0.73)$ & \\
\hline
\end{tabular}

the patterns seen in the stratified analyses: household income, needing help with basic tasks, and self-perceived mental health. Table 2 provides the results from this analysis for any hospital use, and Additional File 6 provides the results for any emergency department visit. Twelve regression models were run (three variables $\mathrm{x}$ four age/sex strata) for each type of acute care use, with very few models showing significant interactions. Only two of the twelve models showed a significant interaction effect for any hospital use $(p=0.0009$, self-perceived mental health in males 75-84 years; $p=0.0001$, needing help with basic tasks in females $75-84$ years) and only one model showed a significant interaction effect for any emergency department use ( $p=0.04$, household income in females 65-74).

\section{Multivariable regression results}

In an unadjusted regression model, the odds of any hospitalization for those with $2-3$ and $4+$ chronic conditions compared to $0-1$ chronic conditions was 1.74 and 3.30 , respectively. Table 3 shows the results for the adjusted multiple regression models for any hospitalization and the number of hospitalizations, with all correlates simultaneously included in the model. The ORs for multimorbidity are reduced once other correlates are 


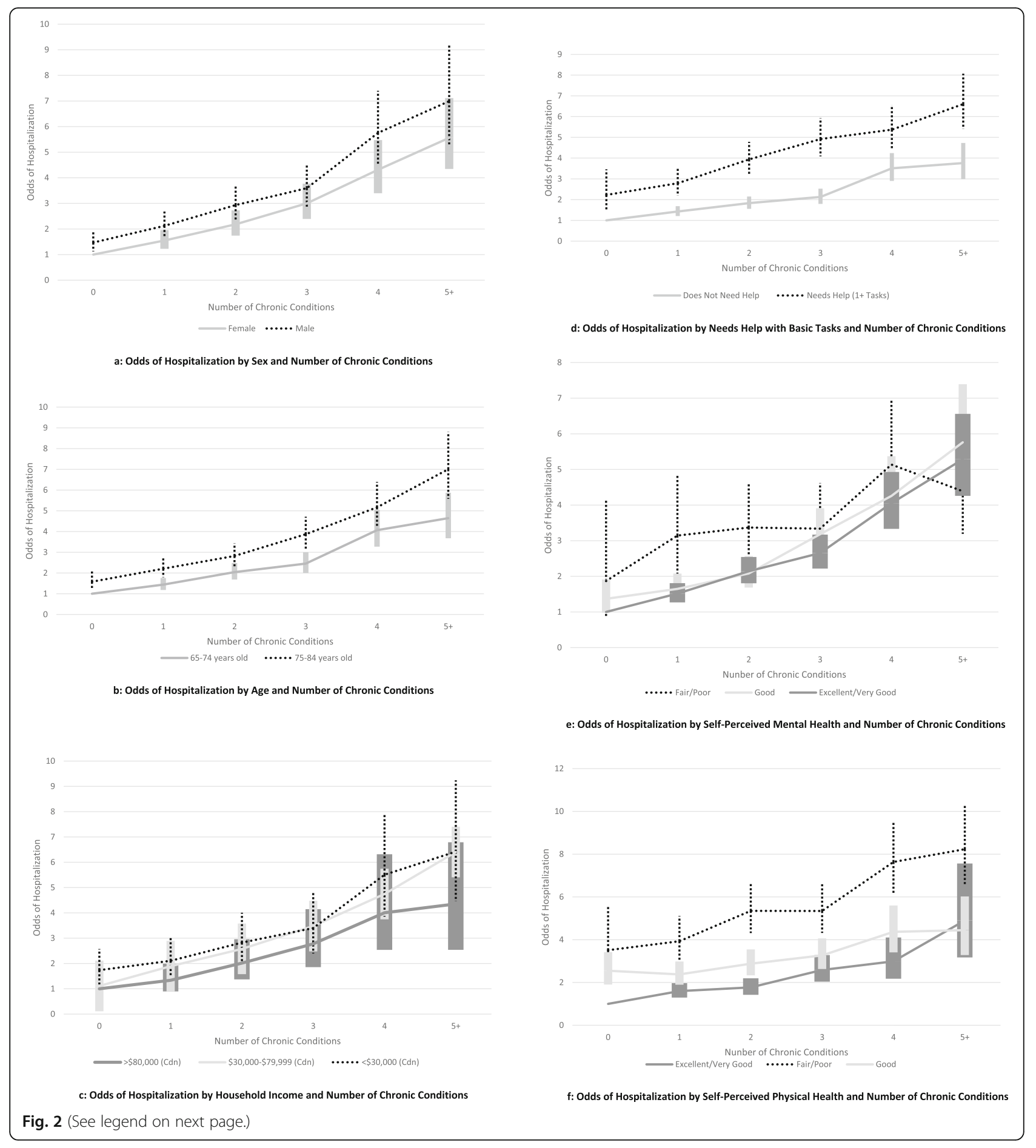


(See figure on previous page.)

Fig. 2 a-f. a: Odds of Hospitalization by Sex and Number of Chronic Conditions. b: Odds of Hospitalization by Age and Number of Chronic Conditions. c: Odds of Hospitalization by Household Income and Number of Chronic Conditions. Odds of Hospitalization by Needs Help with Basic Tasks and Number of Chronic Conditions. e: Odds of Hospitalization by Self-Perceived Mental Health and

Number of Chronic Conditions. f: Odds of Hospitalization by SelfPerceived Physical Health and Number of Chronic Conditions

included in the model (to 1.31 for $2-3$ chronic conditions and 1.84 for $4+$ ), but remain statistically significant in both models. The results were similar for both outcomes (any hospitalization, number of hospitalizations), with higher odds (or incidence) of hospitalization seen in those with higher levels of multimorbidity, in older respondents, lower household income, lower perceived physical health, and in those that were male, nonimmigrant, needed help with basic tasks or lived alone. Odds of hospitalization were lower in those with lower perceived mental health. Education and residency (urban/rural) were not associated with either hospitalization outcome.

In the unadjusted regression model, the odds of any emergency department visit for those with 2-3 and 4+ chronic conditions compared to $0-1$ chronic conditions were 1.53 and 2.84, respectively. Additional File 7 shows the results of the adjusted multiple regression for any ED visit and the number of ED visits. The ORs for multimorbidity are reduced once other correlates are included in the model (to 1.21 for $2-3$ chronic conditions and 1.75 for $4+$ ), but remain statistically significant in both models. The results for both outcomes (any emergency department use, number of emergency department visits) were similar and largely consistent with those discussed above for hospitalizations.

\section{Age and sex differences in service use}

We explored service use differences by age and sex, since some studies report age/sex influences on health care use and/or cost. Figure $3 \mathrm{a}$ and $\mathrm{b}$ compare males and females respectively on the average hospitalization and ED use (among those with at least one ED visit or hospitalization) across age/multimorbidity strata. These figures do not suggest major sex differences across the age/multimorbidity strata. The largest difference between males and females occurs in the highest multimorbidity/age category $(4+, 75-$ 84) for ED visits, where females remain the same but males decline in use from an average of 2.0 to 1.5 visits compared to the lower multimorbidity category (2-3, 75-84).

\section{Discussion}

\section{Summary of main findings}

This study is one of the few to examine the influence of a comprehensive range of socio-demographic factors and health status factors on the relationship between multimorbidity and acute care service use. Our main interest was the role of these factors in moderating the association between multimorbidity and acute care service use. We did not observe strong evidence of moderator or interaction effects across this comprehensive range of factors. While most of the factors influenced acute care service use independent of multimorbidity, they did not change its fundamental relationship with service use - i.e., increased multimorbidity was consistently associated with increased service use for all subgroups.

\section{Comparison with existing literature}

The vast majority of studies to date have examined the independent effects of selected socio-demographic and health status (e.g., multimorbidity) factors on health service use. We are not aware of many studies examining factors moderating the relationship between multimorbidity and service use, or interacting with multimorbidity in shaping service use, with the exception of those looking at age and sex. Overall, we did not find a significant age/sex interaction influencing acute care service use, consistent with other studies, including the study by van den Bussche et al. [19] looking at ambulatory care services and Hessel et al. [24] who studied general practitioner and specialist services. The drop we observed in ED visits for males in the highest multimorbidity/age category $(4+, 75-84)$ compared to the lower multimorbidity/age category $(2-3,75-84)$ is unusual. While Librero et al. [42] reported a similar finding, the review by Lehnert et al. [13] noted that the Librero et al. [42] study was unusual, with all other studies showing a positive association between number of chronic conditions and ED visits. Further research may be help to understand our results (e.g., men in the highest multimorbidity category may spend more time in the hospital compared to the ED, women in the older age groups excluded from this study may show this same pattern).

The effects we observed between socio-demographic and health status factors and acute care service use independent of multimorbidity are consistent with much of the existing literature. The sex differences we observed were not seen in Canadian studies focused on ED use in older adults [43, 44], yet other studies show that older men dominate resource-intensive health care [12, 45-47] perhaps due to men having conditions that require these services [46] or seeking health care only when illness is acute/serious [48]. We observed higher odds of acute care service use in older adults (age 75-84 vs 65-74), for which ample evidence exists [46], including the independent (of 
Table 2 Interaction Effects Analysis for Hospitalizations - Multiple Imputation Results

\begin{tabular}{|c|c|c|c|c|c|}
\hline Sex, Age Group & $\mathrm{MM}^{\mathrm{a}}$ Group & Correlate Group & Overall N (\% with 1+ Hosp) & OR $(95 \% \mathrm{Cl})^{\mathrm{b}}$ & Inter. ${ }^{c}(p$-value) \\
\hline \multicolumn{6}{|c|}{ Interaction \#1: MM x Income } \\
\hline \multirow[t]{9}{*}{ Female, 65-74 } & $0-1$ & $>\$ 80 k$ & $640(3)$ & Ref & 0.11 \\
\hline & & $\$ 30 \mathrm{k}-\$ 79.9 \mathrm{k}$ & $1950(7)$ & $2.25(1.39,3.63)$ & \\
\hline & & $<\$ 30 k$ & $1286(6)$ & $1.95(1.18,3.22)$ & \\
\hline & $2-3$ & $>\$ 80 k$ & $507(8)$ & Ref & \\
\hline & & $\$ 30 k-\$ 79.9 k$ & $1955(10)$ & $1.22(0.86,1.74)$ & \\
\hline & & $<\$ 30 k$ & $1672(11)$ & $1.36(0.96,1.94)$ & \\
\hline & $4+$ & $>\$ 80 k$ & $108(15)$ & Ref & \\
\hline & & $\$ 30 k-\$ 79.9 k$ & $563(16)$ & $1.08(0.60,1.92)$ & \\
\hline & & $<\$ 30 k$ & $749(20)$ & $1.42(0.81,2.48)$ & \\
\hline \multirow[t]{9}{*}{ Female, 75-84 } & $0-1$ & $>\$ 80 k$ & $210(9)$ & Ref & 0.20 \\
\hline & & $\$ 30 k-\$ 79.9 k$ & $937(7)$ & $0.82(0.47,1.41)$ & \\
\hline & & $<\$ 30 k$ & $962(10)$ & $1.20(0.71,2.03)$ & \\
\hline & $2-3$ & $>\$ 80 k$ & $285(9)$ & Ref & \\
\hline & & $\$ 30 \mathrm{k}-\$ 79.9 \mathrm{k}$ & $1421(15)$ & 1.65 (1.08. 2.51) & \\
\hline & & $<\$ 30 k$ & $1719(15)$ & $1.63(1.08,2.48)$ & \\
\hline & $4+$ & $>\$ 80 k$ & $102(20)$ & Ref & \\
\hline & & $\$ 30 k-\$ 79.9 k$ & $429(23)$ & $1.21(0.71,2.08)$ & \\
\hline & & $<\$ 30 k$ & $773(24)$ & $1.32(0.79,2.21)$ & \\
\hline \multirow[t]{9}{*}{ Male, 65-74 } & $0-1$ & $>\$ 80 k$ & $911(7)$ & Ref & 0.52 \\
\hline & & $\$ 30 k-\$ 79.9 k$ & $1805(7)$ & $1.10(0.80,1.51)$ & \\
\hline & & $<\$ 30 k$ & $804(10)$ & $1.61(1.14,2.28)$ & \\
\hline & $2-3$ & $>\$ 80 k$ & $686(11)$ & Ref & \\
\hline & & $\$ 30 \mathrm{k}-\$ 79.9 \mathrm{k}$ & $1752(13)$ & $1.26(0.95,1.66)$ & \\
\hline & & $<\$ 30 k$ & 798 (14) & $1.36(0.99,1.87)$ & \\
\hline & $4+$ & $>\$ 80 k$ & $107(16)$ & Ref & \\
\hline & & $\$ 30 \mathrm{k}-\$ 79.9 \mathrm{k}$ & $407(23)$ & $1.57(0.89,2.77)$ & \\
\hline & & $<\$ 30 k$ & $279(25)$ & $1.77(0.99,3.19)$ & \\
\hline \multirow[t]{9}{*}{ Male, 75-84 } & $0-1$ & $>\$ 80 k$ & $253(8)$ & Ref & 0.65 \\
\hline & & $\$ 30 k-\$ 79.9 k$ & $866(12)$ & $1.47(0.90,2.41)$ & \\
\hline & & $<\$ 30 k$ & $483(16)$ & $2.06(1.24,3.43)$ & \\
\hline & $2-3$ & $>\$ 80 k$ & $350(15)$ & Ref & \\
\hline & & $\$ 30 \mathrm{k}-\$ 79.9 \mathrm{k}$ & $1238(17)$ & $1.15(0.83,1.59)$ & \\
\hline & & $<\$ 30 k$ & $616(20)$ & $1.34(0.94,1.90)$ & \\
\hline & $4+$ & $>\$ 80 k$ & $97(21)$ & Ref & \\
\hline & & $\$ 30 \mathrm{k}-\$ 79.9 \mathrm{k}$ & $400(28)$ & $1.46(0.85,2.50)$ & \\
\hline & & $<\$ 30 k$ & $241(30)$ & $1.64(0.93,2.88)$ & \\
\hline \multicolumn{6}{|c|}{ Interaction \#2: MM x Self-Perceived Mental Health } \\
\hline \multirow[t]{6}{*}{ Female, 65-74 } & $0-1$ & Excellent & $3192(6)$ & Ref & 0.97 \\
\hline & & Good & $627(7)$ & $1.15(0.81,1.63)$ & \\
\hline & & Fair/Poor & $57(<11)^{d}$ & $1.24(0.44,3.47)$ & \\
\hline & $2-3$ & Excellent & $3040(9)$ & Ref & \\
\hline & & Good & $900(12)$ & $1.27(1.00,1.62)$ & \\
\hline & & Fair/Poor & $194(12)$ & $1.31(0.83,2.06)$ & \\
\hline
\end{tabular}


Table 2 Interaction Effects Analysis for Hospitalizations - Multiple Imputation Results (Continued)

\begin{tabular}{|c|c|c|c|c|c|}
\hline Sex, Age Group & $M^{\mathrm{a}}$ Group & Correlate Group & Overall N (\% with $1+$ Hosp) & OR $(95 \% \mathrm{CI})^{\mathrm{b}}$ & Inter. $^{c}(p$-value $)$ \\
\hline & $4+$ & Excellent & $828(17)$ & Ref & \\
\hline & & Good & $415(19)$ & $1.12(0.82,1.52)$ & \\
\hline & & Fair/Poor & $177(20)$ & $1.26(0.83,1.89)$ & \\
\hline \multirow[t]{9}{*}{ Female, 75-84 } & $0-1$ & Excellent & $1633(8)$ & Ref & 0.53 \\
\hline & & Good & $435(9)$ & $1.12(0.77,1.63)$ & \\
\hline & & Fair/Poor & $41(17)$ & $2.28(0.99,5.25)$ & \\
\hline & $2-3$ & Excellent & $2404(14)$ & Ref & \\
\hline & & Good & $864(15)$ & $1.05(0.84,1.31)$ & \\
\hline & & Fair/Poor & $257(16)$ & $1.17(0.75,1.82)$ & \\
\hline & $4+$ & Excellent & $740(23)$ & Ref & \\
\hline & & Good & $383(24)$ & $1.04(0.78,1.40)$ & \\
\hline & & Fair/Poor & $181(23)$ & $0.99(0.68,1.47)$ & \\
\hline \multirow[t]{9}{*}{ Male, 65-74 } & $0-1$ & Excellent & $2792(8)$ & Ref & 0.65 \\
\hline & & Good & $643(8)$ & $1.06(0.77,1.46)$ & \\
\hline & & Fair/Poor & $85(13)$ & $1.83(0.96,3.50)$ & \\
\hline & $2-3$ & Excellent & $2257(13)$ & Ref & \\
\hline & & Good & $805(12)$ & $0.96(0.75,1.22)$ & \\
\hline & & Fair/Poor & $174(13)$ & $1.05(0.67,1.66)$ & \\
\hline & $4+$ & Excellent & $444(21)$ & Ref & \\
\hline & & Good & $242(23)$ & $1.10(0.75,1.60)$ & \\
\hline & & Fair/Poor & $107(29)$ & $1.52(0.94,2.44)$ & \\
\hline \multirow[t]{9}{*}{ Male, 75-84 } & $0-1$ & Excellent & $1173(12)$ & Ref & 0.0009 \\
\hline & & Good & $371(13)$ & $1.19(0.84,1.68)$ & \\
\hline & & Fair/Poor & $58(22)$ & $2.20(1.16,4.19)$ & \\
\hline & $2-3$ & Excellent & $1459(17)$ & Ref & \\
\hline & & Good & $597(17)$ & $1.03(0.80,1.33)$ & \\
\hline & & Fair/Poor & $148(30)$ & $2.11(1.45,3.09)$ & \\
\hline & $4+$ & Excellent & 407 (29) & Ref & \\
\hline & & Good & $208(30)$ & $1.07(0.74,1.54)$ & \\
\hline & & Fair/Poor & $123(20)$ & $0.61(0.37,1.00)$ & \\
\hline \multicolumn{6}{|c|}{ Interaction \# 3: MM x Instrumental Activities of Daily Living } \\
\hline \multirow[t]{6}{*}{ Female, 65-74 } & $0-1$ & Does not need help & $3575(5)$ & Ref & 0.49 \\
\hline & & Needs help & $301(12)$ & $2.48(1.71,3.61)$ & \\
\hline & $2-3$ & Does not need help & $3372(8)$ & Ref & \\
\hline & & Needs help & $762(17)$ & $2.27(1.81,2.84)$ & \\
\hline & $4+$ & Does not need help & $833(14)$ & Ref & \\
\hline & & Needs help & $587(24)$ & $1.92(1.46,2.52)$ & \\
\hline \multirow[t]{6}{*}{ Female, 75-84 } & $0-1$ & Does not need help & $1750(8)$ & Ref & 0.0001 \\
\hline & & Needs help & $359(12)$ & $1.64(1.14,2.34)$ & \\
\hline & $2-3$ & Does not need help & $2235(10)$ & Ref & \\
\hline & & Needs help & $1190(22)$ & $2.38(1.96,2.89)$ & \\
\hline & $4+$ & Does not need help & $526(22)$ & Ref & \\
\hline & & Needs help & $778(25)$ & $1.18(0.91,1.54)$ & \\
\hline Male, $65-74$ & $0-1$ & Does not need help & $3373(7)$ & Ref & 0.89 \\
\hline
\end{tabular}


Table 2 Interaction Effects Analysis for Hospitalizations - Multiple Imputation Results (Continued)

\begin{tabular}{|c|c|c|c|c|c|}
\hline Sex, Age Group & $M^{\mathrm{a}}$ Group & Correlate Group & Overall N (\% with 1+ Hosp) & OR $(95 \% \mathrm{Cl})^{\mathrm{b}}$ & Inter. ${ }^{c}(p$-value) \\
\hline & & Needs help & $147(16)$ & $2.33(1.46,3.70)$ & \\
\hline & $2-3$ & Does not need help & $2895(11)$ & Ref & \\
\hline & & Needs help & $341(22)$ & $2.18(1.64,2.88)$ & \\
\hline & $4+$ & Does not need help & $575(18)$ & Ref & \\
\hline & & Needs help & $218(35)$ & $2.42(1.71,3.44)$ & \\
\hline \multirow[t]{6}{*}{ Male, 75-84 } & $0-1$ & Does not need help & $1430(11)$ & Ref & 0.25 \\
\hline & & Needs help & $172(20)$ & $1.98(1.31,2.96)$ & \\
\hline & $2-3$ & Does not need help & $1752(15)$ & Ref & \\
\hline & & Needs help & $452(29)$ & $2.36(1.85,3.01)$ & \\
\hline & $4+$ & Does not need help & $416(23)$ & Ref & \\
\hline & & Needs help & $322(33)$ & $1.68(1.21,2.33)$ & \\
\hline
\end{tabular}

multimorbidity) age effects seen in Payne et al.'s [49] large general population study and studies of various disease cohorts [50,51]. Our finding that lower household income and education were associated with higher odds of acute care service use is consistent with another Canadian study [7] and others using a range of individual and/or regional socioeconomic status measures $[17,18,52]$. We observed that non-immigrants had higher use of acute care services compared to immigrants, consistent with Roberge et al.'s Canadian study on ED use [53] and thought to reflect the better health of new immigrants or language/knowledgerelated access barriers [54]. We found higher ED use (not hospitalizations) among rural versus urban residents, which has been reported by other Canadian studies [53, 55] and attributed to access barriers or a perceived need for specialized services $[56,57]$ as well as the tendency of rural physicians to practice in EDs and hospitals and thus encourage patients to use these services $[58,59]$. Our study found that low/poor self-perceived health and functionality were linked to higher acute care service use, consistent with other studies [60-63] and research showing that adding functional status to administrative-based chronic illness data improves the ability to identify high risk/high-cost system users $[60,64]$. We found that lower perceived self-reported mental health was associated with lower hospital use (not ED use), unlike studies that show that mental health disorders are a key driver of higher ED use $[65,66]$. However, we used self-reported mental health, which differs from objective (diagnostic-based) measures of mental illness [67-69], which may explain study differences. We also found that living alone was associated with higher hospitalizations (not ED use) as seen in some studies [70,71] and not others [72], which is broadly consistent with a systematic review linking weaker social relationships with increased hospitalizations [73], associations seen between social isolation/loneliness and poor health $[74,75]$ and findings that social isolation/loneliness predicts ED use [66, 76-80].

\section{Implications of study findings for research, Policy \& Practice}

While our data showed that multimorbidity impacts on acute care service use similarly across most sociodemographic and health variables, it also shows that these variables have their own direct effect on acute care service use and should be considered in intervention development, resource targeting, and future research. The message appears to be - multimorbidity impacts acute care service use consistently and similarly across many population subgroups.

Our results suggest that we cannot ignore population subgroups where there is consistent evidence pointing to a higher risk of acute care service use, or where there are inconsistent findings that require further research. The multiple regression results from this study show that a number of factors are linked to higher acute care service use, independent of multimorbidity. Age is a strong predictor of health service use across many studies, thus targeting resources and designing interventions to support older age groups is warranted to enhance access to community-based supports and assist them in managing conditions other than chronic conditions that may explain higher acute care use (e.g., geriatric syndromes such as frailty, incontinence, pain). Physical health and functionality, which are linked to age and multimorbidity but also independent of these, are strong predictors of service use in many studies. Taking a broader view of physical health that includes functional 
Table 3 Odds Ratios and Incidence Rates of Hospitalization, Multiple Imputation Results

\begin{tabular}{|c|c|c|}
\hline Variable & OR $[95 \% \mathrm{Cl}]^{\mathrm{a}}$ & IR $[95 \% \mathrm{CI}]^{\mathrm{a}}$ \\
\hline \multicolumn{3}{|l|}{ Chronic Conditions } \\
\hline $0-1$ & - & - \\
\hline $2-3$ & $1.31[1.20,1.44]$ & $1.35[1.24,1.47]$ \\
\hline $4+$ & $1.84[1.64,2.06]$ & $1.80[1.61,2.00]$ \\
\hline \multicolumn{3}{|l|}{ Age } \\
\hline $65-74$ & - & - \\
\hline $75-84$ & $1.32[1.22,1.42]$ & $1.29[1.20,1.39]$ \\
\hline \multicolumn{3}{|l|}{ Sex } \\
\hline Female & - & - \\
\hline Male & $1.45[1.34,1.57]$ & $1.43[1.32,1.54]$ \\
\hline \multicolumn{3}{|l|}{ Immigrant Status } \\
\hline Immigrant & - & - \\
\hline Non-Immigrant & $1.16[1.06,1.26]$ & $1.14[1.05,1.24]$ \\
\hline \multicolumn{3}{|l|}{ Education } \\
\hline Post-secondary degree & - & - \\
\hline Secondary school degree & $0.95[0.86,1.05]$ & $0.98[0.89,1.08]$ \\
\hline No diploma & $1.08[0.99,1.18]$ & $1.11[1.02,1.21]$ \\
\hline \multicolumn{3}{|l|}{ Household Income } \\
\hline Over $\$ 80,000$ & - & - \\
\hline$\$ 30,000$ to $\$ 79,999$ & $1.22[1.07,1.38]$ & $1.30[1.15,1.47]$ \\
\hline Under $\$ 30,000$ & $1.22[1.06,1.40]$ & $1.28[1.12,1.47]$ \\
\hline \multicolumn{3}{|l|}{ Living Arrangement } \\
\hline Living with others & - & - \\
\hline Living alone & $1.15[1.06,1.25]$ & $1.12[1.04,1.22]$ \\
\hline \multicolumn{3}{|l|}{ Geography } \\
\hline Urban & - & - \\
\hline Rural & $1.04[0.96,1.14]$ & $1.05[0.96,1.13]$ \\
\hline \multicolumn{3}{|c|}{ Instrumental Activities of Daily Living (IADLs) } \\
\hline Does not need help with basic tasks & - & - \\
\hline Needs help with basic tasks & $1.68[1.54,1.84]$ & $1.58[1.45,1.72]$ \\
\hline \multicolumn{3}{|l|}{ Self-Perceived Physical Health } \\
\hline Excellent/Very Good & - & - \\
\hline Good & $1.50[1.36,1.65]$ & $2.30[2.08,2.55]$ \\
\hline Fair or Poor & $2.29[2.05,2.54]$ & $1.51[1.37,1.65]$ \\
\hline \multicolumn{3}{|l|}{ Self-Perceived Mental Health } \\
\hline Excellent & - & - \\
\hline Good & $0.88[0.81,0.97]$ & $0.90[0.83,0.98]$ \\
\hline Fair or Poor & $0.79[0.68,0.93]$ & $0.84[0.73,0.97]$ \\
\hline
\end{tabular}

limitations and self-reported health status measures can be a source of potent predictors of service needs/use. Including these measures in standard clinical assessments can be done, which could then inform resource targeting and intervention design. Consistent evidence links low socioeconomic status with higher acute care service use, even in Canada where there is a national system of health and social services. This socioeconomic gradient is independent of multimorbidity, which itself is more prevalent in socioeconomically-deprived populations [81]. Targeting resources and interventions at low socioeconomic groups can help to remove barriers to 


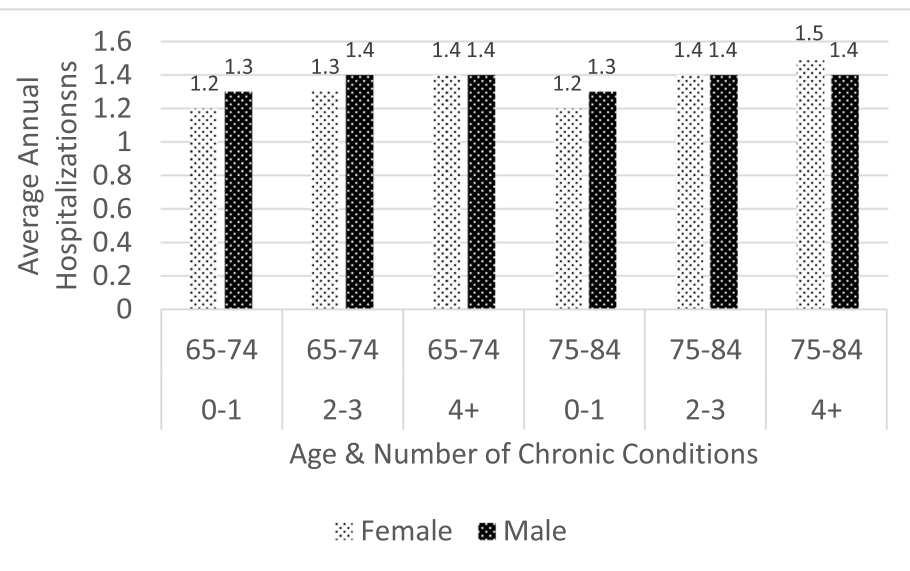

a: Average 1-Year Hospital Use by Sex, Age and Number of Chronic Conditions

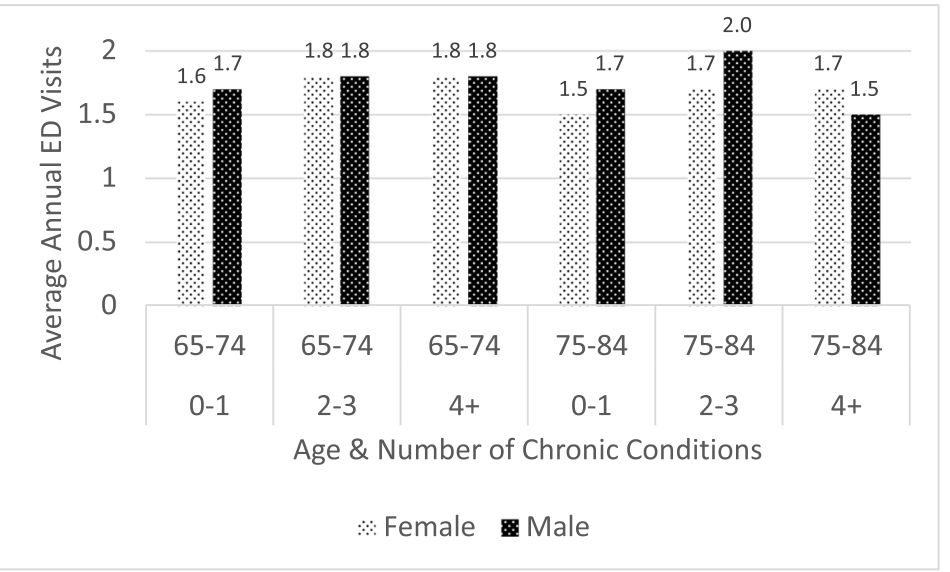

b: Average 1-Year Emergency Department Use by Sex, Age and Number of Chronic Conditions

Fig. 3 a and b: a: Average 1-Year Hospital Use by Sex, Age and Number of Chronic Conditions. b: Average 1-Year Emergency Department Use by Sex, Age and Number of Chronic Conditions

accessing healthcare services [82] and avoid the cascading effects resulting from developing poorer health outcomes that require more expensive healthcare services [7]. Some factors require further research in order to determine if an intervention is needed and what it should target. For example, immigrant's use of acute care services is less than non-immigrant's use, but why does this reflect health differences or access barriers? Rural residents use more acute care services, but why does this reflect the need for specialized or immediate services, accessibility, or family physician directives? Studies from Canada [55, 83] and the U.S. [84] suggest that high users of primary care are also high ED users, so access may not be the main driver in the acute care service use of rural residents. Mental health and living status may either increase, decrease or not affect acute care service use. These differences need to be better understood, and would likely benefit from the use of better and more consistent construct measures.

Finally, this study should be seen as part of an ongoing research agenda aimed at untangling the complex relationships between multimorbidity, health service use, and various socio-demographic and health status variables. Important next steps include longitudinal research to explore the potential mediating role that these variables may play in the relationship between multimorbidity and health service use.

\section{Strengths and limitations}

A major strength of this study was the use of a large sample of Canadian older adults and administrative data with robust and well-reported measures of chronic conditions and accurate capture of health service use. By linking to the CCHS, we were able to incorporate a 
comprehensive range of sociodemographic variables that are typically not available when using administrative data alone. Other strengths include minimal missing data, and modelling acute care service outcomes two different ways (any service and number of services) showing that this methodological choice did not significantly impact the findings from the multiple regression.

We also acknowledge the key limitations of our study. Our measure of multimorbidity included 12 chronic conditions. These conditions represent the most prevalent chronic conditions in Canadian older adults [85] and those often used in multimorbidity research [86]. However, there are conditions other than those captured in this study that may influence healthcare service use. Also, our measure of multimorbidity - the number of chronic conditions - does not capture differences in the types/clusters/severity of the conditions, which can also impact healthcare service use. Essentially, we still lack a consistent definition or framework for thinking about multimorbidity, which impacts research and the comparability of studies [14]. Our study also uses data from a large national survey (the CCHS), which has limitations including potential biases related to self-report data (e.g., response bias, recall bias) and module changes that limit comparing across or pooling CCHS cycles. Our study focused on acute care (hospital, emergency department) services; it would be useful to examine primary care and other service use for a more comprehensive understanding of impacts. We explored specific interactions between multimorbidity and the covariates, which was necessarily selective due to the large number of covariates in the study. Although few interaction terms were significant in the regressions, it is possible that some relevant interactions were missed.

\section{Conclusion}

This study examined the relationship between multimorbidity and acute care service use and how various sociodemographic and health factors impact this relationship. The study did not reveal strong evidence of moderator or interaction effects across the range of factors, suggesting that multimorbidity interventions can be delivered broadly. Multimorbidity is consistently and similarly associated with acute care service use across many population subgroups, thus it is important to continue multimorbidity research to better understand its origins and impacts and target resources/programs to better manage it. This study also found that many factors influenced acute care service use independent of multimorbidity, pointing to modifiable risk factors that can be the focus of resource allocation and intervention design to reduce acute care service in those with multimorbidity.
Ultimately, the study's results suggest that optimizing acute care service use in older adults will require attention to both multimorbidity and social determinants, with programs that are multifactorial and integrated across the health and social service sectors.

\section{Supplementary Information}

The online version contains supplementary material available at https://doi. org/10.1186/s12913-020-06032-5.

Additional file 1. Institute for Clinical Evaluative Science (ICES) Database Details.

Additional file 2. Diagnostic Definitions for 12 Chronic Conditions.

Additional file 3. Canadian Community Health Study Covariates, Operationalization, and Percent Missing.

Additional file 4. Remaining Stratified Figures for Odds of Hospitalization.

Additional file 5. Stratified Figures for Odds of Emergency Dept Visit. Additional file 6. Interaction Effects Analysis for Emergency Department Visits - Multiple Imputation Results.

Additional file 7. Odds Ratios and Incidence Rates of Emergency Department Visits - Multiple Imputation Results.

\section{Abbreviations}

ADL: Activities of Daily Living; CCHS: Canadian Community Health Survey; COPD: Chronic Obstructive Pulmonary Disease; ED: Emergency Department; IADL: Instrumental Activities of Daily Living; ICES: Institute for Clinical Evaluative Sciences; LCL: Lower 95\% Confidence Limit; OHIP: Ontario Health Insurance Plan; OR: Odds Ratio; UCL: Upper 95\% Confidence Limit

\section{Acknowledgements}

Not applicable.

\section{Authors' contributions}

$L G, A G, K F, R U$, JP and MMR developed the study design. RP, LF and FN conducted the analysis under the direction of $L G, A G$ and $K F . L G, A G, K F, R P$, $L F, R U$ and $F N$ participated in the interpretation of the analyses. KF prepared the initial draft of the manuscript. All authors reviewed and commented on the manuscript draft, and approved the final version of the manuscript submitted for publication.

\section{Funding}

This work is part of a program of research (Aging, Community and Health Research Unit) supported by the Canadian Institutes of Health Research Signature Initiative in Community- Based Primary Healthcare (http://www. cihr-irsc.gc.ca/e/43626.html) (Funding Reference Number: TTF 128261) and the Ontario Ministry of Health and Long-Term Care Health System Research Fund Program (Grant \#06669)". The funding agencies provided financial support for the study, but did not participate in the design or execution of the study and were not involved in the preparation of this manuscript.

\section{Availability of data and materials}

The data that support the findings of this study are available from the Institute for Clinical Evaluative Sciences (ICES), an independent, non-profit research institute funded by an annual grant from the Ontario Ministry of Health and Long-Term Care. However, restrictions apply to the availability of these data, which were used under license for the current study, and so are not publicly available. Those interested in acquiring these data must submit an application to ICES.

\section{Ethics approval and consent to participate}

The study received approval from the Hamilton Integrated Research Ethics Board at McMaster University (certificate \#13-590) and renewed yearly as required.

Administrative data and Canadian Community Health Survey (CCHS) data were obtained from the Institute for Clinical Evaluative Sciences (ICES), an 
independent, non-profit research institute funded by an annual grant from the Ontario Ministry of Health and Long-Term Care. As a prescribed entity under Ontario's privacy legislation, ICES is authorized to collect and use health care data for the purposes of health system analysis, evaluation and decision support. Secure access to these data is governed by policies and procedures that are approved by the Information and Privacy Commissioner of Ontario.

\section{Consent for publication}

Not applicable.

\section{Competing interests}

The authors declare that they have no competing interests.

\section{Author details}

'School of Nursing, McMaster University, HSC 2J36, 1280 Main Street West, Hamilton, Ontario L8S 4K1, Canada. ${ }^{2}$ Department of Health Research Methods, Evidence, and Impact, McMaster University, CRL Building, First Floor, 1280 Main Street West, Hamilton, Ontario L8S 4K1, Canada. ${ }^{3}$ Department of Family Medicine, University of Alberta, 6-10 University TerraceEdmonton, AB T6G 2T4, Edmonton, Alberta T6G 2R3, Canada. ${ }^{4}$ ICES, 2075 Bayview Ave, Toronto, Ontario M4N 3M5, Canada. ${ }^{5}$ Division of Clinical Public Health, Dalla Lana School of Public Health, 155 College St. Room 690, Toronto, ON M5T 3M7 University of Toronto, Toronto, Ontario, Canada. ${ }^{6}$ Institute for Clinical Evaluative Sciences (ICES), McMaster University, HSC 4N43, 1280 Main Street West, Hamilton, Ontario L8S 4K1, Canada.

Received: 23 June 2020 Accepted: 20 December 2020

Published online: 13 January 2021

\section{References}

1. Salive ME. Multimorbidity in older adults. Epidemiol Rev. 2013;35:75-83.

2. Fortin M, Bravo G, Hudon C, Vanasse A, Lapointe L. Prevalence of multimorbidity among adults seen in family practice. Ann Fam Med. 2005; 3(3):223-8.

3. Barnett K, Mercer SW, Norbury M, Watt G, Wyke S, Guthrie B. Epidemiology of multimorbidity and implications for health care, research, and medical education: a cross-sectional study. Lancet. 2012;380(9836):37-43.

4. Uijen AA, van de Lisdonk EH. Multimorbidity in primary care: prevalence and trend over the last 20 years. Eur J Gen Pract. 2008;14(Suppl 1):28-32.

5. Agborsangaya CB, Ngwakongnwi E, Lahtinen M, Cooke T, Johnson JA. Multimorbidity prevalence in the general population: the role of obesity in chronic disease clustering. BMC Public Health. 2013;13:1161.

6. Wolff JL, Starfield B, Anderson G. Prevalence, expenditures, and complications of multiple chronic conditions in the elderly. Arch Intern Med. 2002;162(20):2269-76

7. Pefoyo AJ, Bronskill SE, Gruneir A, Calzavara A, Thavorn K, Petrosyan Y, et al. The increasing burden and complexity of multimorbidity. BMC Public Health. 2015;15:415.

8. van Oostrom SH, Gijsen R, Stirbu I, Korevaar JC, Schellevis FG, Picavet HS, et al. Time trends in prevalence of chronic diseases and multimorbidity not only due to aging: data from general practices and health surveys. PLoS One. 2016;11(8):e0160264.

9. Freid VM, Bernstein AB, Bush MA. Multiple chronic conditions among adults aged 45 and over: trends over the past 10 years. NCHS Data Brief. 2012;100:1-8.

10. Bayliss EA, Bayliss MS, Ware JE Jr, Steiner JF. Predicting declines in physical function in persons with multiple chronic medical conditions: what we can learn from the medical problem list. Health Qual Life Outcomes. 2004;2:47.

11. Williams JS, Egede LE. The association between multimorbidity and quality of life, health status and functional disability. Am J Med Sci. 2016;352(1):45-52

12. Emerging Risk Factors C, Di Angelantonio E, Kaptoge S, Wormser D, Willeit $P$, Butterworth AS, et al. Association of Cardiometabolic Multimorbidity with Mortality. JAMA. 2015;314(1):52-60.

13. Lehnert T, Heider D, Leicht H, Heinrich S, Corrieri S, Luppa M, et al. Review: health care utilization and costs of elderly persons with multiple chronic conditions. Med Care Res Rev. 2011;68(4):387-420.

14. Griffith LE, Gruneir A, Fisher K, Panjwani D, Gafni A, Patterson C, et al. Insights on multimorbidity and associated health service use and costs from three population-based studies of older adults in Ontario with diabetes, dementia and stroke. BMC Health Serv Res. 2019:19(1):313.

15. McPhail SM. Multimorbidity in chronic disease: impact on health care resources and costs. Risk Manag Healthc Policy. 2016:9:143-56.

16. Frolich A, Ghith Nermin, Schiotz Michaela, Jacobsen Ramune, Stockmarr Anders. Multimorbidity and healthcare utilization: A register-based study in Denmark 2019:1-27.

17. Bahler C, Huber CA, Brungger B, Reich O. Multimorbidity, health care utilization and costs in an elderly community-dwelling population: a claims data based observational study. BMC Health Serv Res. 2015;15:23.

18. Glynn LG, Valderas JM, Healy P, Burke E, Newell J, Gillespie P, et al. The prevalence of multimorbidity in primary care and its effect on health care utilization and cost. Fam Pract. 2011;28(5):516-23.

19. van den Bussche $H$, Schon G, Kolonko T, Hansen H, Wegscheider K, Glaeske $\mathrm{G}$, et al. Patterns of ambulatory medical care utilization in elderly patients with special reference to chronic diseases and multimorbidity--results from a claims data based observational study in Germany. BMC Geriatr. 2011;11:54.

20. van Oostrom SH, Picavet HS, de Bruin SR, Stirbu I, Korevaar JC, Schellevis FG, et al. Multimorbidity of chronic diseases and health care utilization in general practice. BMC Fam Pract. 2014;15:61.

21. Violan C, Foguet-Boreu Q, Roso-Llorach A, Rodriguez-Blanco T, Pons-Vigues $M$, Pujol-Ribera $E$, et al. Burden of multimorbidity, socioeconomic status and use of health services across stages of life in urban areas: a cross-sectional study. BMC Public Health. 2014;14:530.

22. Landi F, Onder G, Cesari M, Barillaro C, Lattanzio F, Carbonin PU, et al. Comorbidity and social factors predicted hospitalization in frail elderly patients. J Clin Epidemiol. 2004;57(8):832-6.

23. Fortin M, Hudon C, Haggerty J, Akker M, Almirall J. Prevalence estimates of multimorbidity: a comparative study of two sources. BMC Health Serv Res. 2010;10:111

24. Hessel A, Gunzelmann T, Geyer M, Brahler E. Utilization of medical services and medication intake of patients over 60 in Germany--health related, social structure related, socio-demographic and subjective factors. Z Gerontol Geriatr. 2000;33(4):289-99.

25. Griffith LE, Gruneir A, Fisher KA, Nicholson K, Panjwani D, Patterson C, et al. Key factors to consider when measuring multimorbidity: Results from an expert panel and online survey. J Comorb. 2018:8(1): $2235042 \times 18795306$

26. Wang HH, Wang JJ, Lawson KD, Wong SY, Wong MC, Li FJ, et al. Relationships of multimorbidity and income with hospital admissions in 3 health care systems. Ann Fam Med. 2015;13(2):164-7.

27. Statistics Canada. Canadian Community Health Survey (CCHS) Cycle 3.1 (2005): Public Use Micro Data File (PUMF) User Guide. Ottawa: Canada Statistics Canada; 2006

28. Statistics Canada. Canadian community health survey (CCHS) annual component: user guide, 2007-2008 microdata files. Statistics Canada: Ottawa; 2009.

29. Statistics Canada. Canadian community health survey (CCHS) annual component: user guide 2010 and 2009-2010 microdata files. Ottara; 2013.

30. Statistics Canada. Canadian community health survey (CCHS) annual component: user guide 2012 and 2011-2012 microdata files. Statistics Canada: Ottawa; 2013.

31. Sinha S, McElhaney J, Rockwood K. Canada's coming of age: how demographic imperatives will force the redesign of acute care service delivery. BC Med J. 2009;51(7):310-1.

32. Griffith LE, Gruneir A, Fisher K, Panjwani D, Gandhi S, Sheng L, et al. Patterns of health service use in community living older adults with dementia and comorbid conditions: a population-based retrospective cohort study in Ontario, Canada. BMC Geriatr. 2016;16(1):177.

33. Steinman MA, Lee SJ, John Boscardin W, Miao Y, Fung KZ, Moore KL, et al. Patterns of multimorbidity in elderly veterans. J Am Geriatr Soc. 2012;60(10): 1872-80.

34. Andersen R, Newman JF. Societal and individual determinants of medical care utilization in the United States. Milbank Mem Fund Q Health Soc. 1973; 51(1):95-124.

35. Andersen RM. Revisiting the behavioral model and access to medical care: does it matter? J Health Soc Behav. 1995:36(1):1-10.

36. Dutton D. Financial, organizational and professional factors affecting health care utilization. Soc Sci Med. 1986:23(7):721-35. 
37. Eve SB. A longitudinal study of use of health care services among older women. J Gerontol. 1988;43(2):M31-9.

38. Mapelli $V$. Health needs, demand for health services and expenditure across social groups in Italy: an empirical investigation. Soc Sci Med. 1993;36(8): 999-1009.

39. Padgett DK, Brodsky B. Psychosocial factors influencing non-urgent use of the emergency room: a review of the literature and recommendations for research and improved service delivery. Soc Sci Med. 1992;35(9):1189-97.

40. Jahangir E, Irazola V, Rubinstein A. Need, enabling, predisposing, and behavioral determinants of access to preventative care in Argentina: analysis of the national survey of risk factors. PLoS One. 2012;7(9): e45053.

41. Yuan Y. Multiple imputation using SAS software. J Stat Softw. 2011;45:1-25.

42. Librero J, Peiro S, Ordinana R. Chronic comorbidity and outcomes of hospital care: length of stay, mortality, and readmission at 30 and 365 days. J Clin Epidemiol. 1999;52(3):171-9.

43. Statistics Canada. Use of Hospital Emergency Rooms Ottawa, ON; 2004 2004. Contract No.: Catalogue 82-003.

44. Centre de recherche de l'Hôpital Charles LeMoyne. Hospital Emergency Departments: Substitutes for Primary Care? Results of a Survey of the Population of Montreal and Monteregie. Montreal: Library and Archives Canada; 2007.

45. Juel K, Christensen K. Are men seeking medical advice too late? Contacts to general practitioners and hospital admissions in Denmark 2005. J Public Health (Oxf). 2008:30(1):111-3.

46. Osika Friberg I, Krantz G, Maatta S, Jarbrink K. Sex differences in health care consumption in Sweden: a register-based cross-sectional study. Scand J Public Health. 2016;44(3):264-73.

47. Mustard CA, Kaufert P, Kozyrskyj A, Mayer T. Sex differences in the use of health care services. N Engl J Med. 1998;338(23):1678-83.

48. Galdas PM, Cheater F, Marshall P. Men and health help-seeking behaviour: literature review. J Adv Nurs. 2005:49(6):616-23.

49. Payne RA, Abel GA, Guthrie B, Mercer SW. The effect of physical multimorbidity, mental health conditions and socioeconomic deprivation on unplanned admissions to hospital: a retrospective cohort study. CMAJ. 2013;185(5):E221-8.

50. Fisher K, Griffith L, Gruneir A, Panjwani D, Gandhi S, Sheng LL, et al. Comorbidity and its relationship with health service use and cost in community-living older adults with diabetes: a population-based study in Ontario, Canada. Diab Res Clin Pract. 2016;122:113-23.

51. van Dijk CE, Verheij RA, Swinkels IC, Rijken M, Schellevis FG, Groenewegen $\mathrm{PP}$, et al. What part of the total care consumed by type 2 diabetes patients is directly related to diabetes? Implications for disease management programs. Int J Integr Care. 2011;11:e140.

52. Violan C, Foguet-Boreu Q, Roso-Llorach A, Rodriguez-Blanco T, Pons-Vigues M, Pujol-Ribera E, et al. Multimorbidity patterns in young adults in Catalonia: an analysis of clusters. Aten Primaria. 2016;48(7):479-92.

53. D. Roberge DL, R. Pineault, JF. Levesque, M. Hamel, B. Simard. Hospital Emergency Departments: Substitutes for Primary Care? Results of a Survey of the Population of Montreal and Monteregie. Montreal: Centre de recherche de l'Hopital Charles LeMoyne; 2007 July, 2007. Report No.: ISBN: 978-2-923595-01-6.

54. Sanmartin C, Ross N. Experiencing difficulties accessing first-contact health services in Canada: Canadians without regular doctors and recent immigrants have difficulties accessing first-contact healthcare services. Reports of difficulties in accessing care vary by age, sex and region. Healthc Policy. 2006;1 (2):103-19.

55. Carriere G. Use of hospital emergency rooms. Ottawa: Statistics Canada 2004 October; 2004.

56. Afilalo J, Marinovich A, Afilalo M, Colacone A, Leger R, Unger B, et al. Nonurgent emergency department patient characteristics and barriers to primary care. Acad Emerg Med. 2004;11(12):1302-10.

57. Sarver JH, Cydulka RK, Baker DW. Usual source of care and nonurgent emergency department use. Acad Emerg Med. 2002;9(9):916-23.

58. Haggerty JL, Roberge $D$, Pineault $R$, Larouche $D$, Touati N. Features of primary healthcare clinics associated with patients' utilization of emergency rooms: urban-rural differences. Healthc Policy. 2007;3(2):72-85.

59. Hodgins MJ, Wuest J. Uncovering factors affecting use of the emergency department for less urgent health problems in urban and rural areas. Can J Nurs Res. 2007;39(3):78-102.
60. Blumenthal KJ, Chang Y, Ferris TG, Spirt JC, Vogeli C, Wagle N, et al. Using a self-reported Global Health measure to identify patients at high Risk for future healthcare utilization. J Gen Intern Med. 2017;32(8):877-82.

61. Fan VS, Au DH, McDonell MB, Fihn SD. Intraindividual change in SF-36 in ambulatory clinic primary care patients predicted mortality and hospitalizations. J Clin Epidemiol. 2004;57(3):277-83.

62. Chandra A, Crane SJ, Tung EE, Hanson GJ, North F, Cha SS, et al. Patientreported geriatric symptoms as risk factors for hospitalization and emergency department visits. Aging Dis. 2015;6(3):188-95.

63. Naseer M, Dahlberg L, Fagerstrom C. Health related quality of life and emergency department visits in adults of age $>/=66$ years: a prospective cohort study. Health Qual Life Outcomes. 2018;16(1):144.

64. Kansagara D, Englander H, Salanitro A, Kagen D, Theobald C, Freeman M, et al. Risk prediction models for hospital readmission: a systematic review. JAMA. 2011:306(15):1688-98.

65. Capp R, Hardy R, Lindrooth R, Wiler J. National Trends in emergency department visits by adults with mental health disorders. J Emerg Med. 2016;51(2):131-5 e1.

66. Behr JG, Diaz R. Emergency department frequent utilization for nonemergent presentments: results from a regional urban trauma center study. PLoS One. 2016;11(1):e0147116.

67. Mawani FN, Gilmour H. Validation of self-rated mental health. Health Rep. 2010;21(3):61-75.

68. Ahmad F, Jhajj AK, Stewart DE, Burghardt M, Bierman AS. Single item measures of self-rated mental health: a scoping review. BMC Health Serv Res. 2014;14:398.

69. Fleishman JA, Zuvekas SH. Global self-rated mental health: associations with other mental health measures and with role functioning. Med Care. 2007; 45(7):602-9.

70. Shaw JG, Farid M, Noel-Miller C, Joseph N, Houser A, Asch SM, et al. Social isolation and Medicare spending: among older adults, objective social isolation increases expenditures while loneliness does not. J Aging Health. 2017;29(7):1119-43.

71. Cafferata GL. Marital status, living arrangements, and the use of health services by elderly persons. J Gerontol. 1987;42(6):613-8.

72. Manski RJ, Moeller JF, Chen H, Schimmel J, St Clair PA, Pepper JV. Patterns of older Americans' health care utilization over time. Am J Public Health. 2013;103(7):1314-24

73. Valtorta NK, Moore DC, Barron L, Stow D, Hanratty B. Older Adults' social relationships and health care utilization: a systematic review. Am J Public Health. 2018;108(4):e1-e10.

74. Barlow MA, Liu SY, Wrosch C. Chronic illness and loneliness in older adulthood: the role of self-protective control strategies. Health Psychol. 2015;34(8):870-9.

75. Cacioppo JT, Cacioppo S. Social relationships and health: the toxic effects of perceived social isolation. Soc Personal Psychol Compass. 2014;8(2):58-72.

76. Lowthian JA, Curtis AJ, Cameron PA, Stoelwinder JU, Cooke MW, McNeil JJ. Systematic review of trends in emergency department attendances: an Australian perspective. Emerg Med J. 2011;28(5):373-7.

77. Genell Andren K, Rosenqvist U. Heavy users of an emergency department--a two year follow-up study. Soc Sci Med. 1987;25(7):825-31.

78. Geller J, Janson P, McGovern E, Valdini A. Loneliness as a predictor of hospital emergency department use. J Fam Pract. 1999;48(10):801-4.

79. Molloy GJ, McGee HM, O'Neill D, Conroy RM. Loneliness and emergency and planned hospitalizations in a community sample of older adults. J Am Geriatr Soc. 2010;58(8):1538-41.

80. Agarwal G, Lee J, McLeod B, Mahmuda SD, Howard M, Cockrell K, Angeles $R$. Social factors in frequent callers: a description of isolation, overty and quality of life in those calling emergency medical services frequently. BMC Public Health. 2019;19:1-8.

81. Kangovi S, Barg FK, Carter T, Long JA, Shannon R, Grande D. Understanding why patients of low socioeconomic status prefer hospitals over ambulatory care. Health Aff (Millwood). 2013;32(7):1 196-203.

82. Williamson DL, Stewart MJ, Hayward K, Letourneau N, Makwarimba E, Masuda $J$, et al. Low-income Canadians' experiences with health-related services: implications for health care reform. Health Policy. 2006;76(1):106-21.

83. Chan BT, Ovens HJ. Frequent users of emergency departments. Do they also use family physicians' services? Can Fam Physician. 2002;48:1654-60.

84. Hunt KA, Weber EJ, Showstack JA, Colby DC, Callaham ML. Characteristics of frequent users of emergency departments. Ann Emerg Med. 2006;48(1):1-8. 
85. Candian Institute for Health Information. Seniors and the health care system: what is the impact of multiple chronic conditions? Ottawa: $\mathrm{CIHI} ; 2011$.

86. Diederichs C, Berger K, Bartels DB. The measurement of multiple chronic diseases-a systematic review on existing multimorbidity indices. J Gerontol A Biol Sci Med Sci. 2011;66(3):301-11.

\section{Publisher's Note}

Springer Nature remains neutral with regard to jurisdictional claims in published maps and institutional affiliations.

- fast, convenient online submission

- thorough peer review by experienced researchers in your field

- rapid publication on acceptance

- support for research data, including large and complex data types

- gold Open Access which fosters wider collaboration and increased citations

- maximum visibility for your research: over $100 \mathrm{M}$ website views per year

At $\mathrm{BMC}$, research is always in progress. 